\title{
Emergency department non-invasive cardiac output study (EDNICO): a feasibility and repeatability study
}

\author{
D. McGregor ${ }^{1 *}$ D, S. Sharma², S. Gupta², S. Ahmad³ ${ }^{3}$ T. Godec ${ }^{4}$ and Tim Harris ${ }^{5}$
}

\begin{abstract}
Background: There is little published data investigating non-invasive cardiac output monitoring in the emergency department (ED). We assessed six non-invasive fluid responsiveness monitoring methods which measure cardiac output directly or indirectly for their feasibility and repeatability of measurements in the ED: (1) left ventricular outflow tract echocardiography derived velocity time integral, (2) common carotid artery blood flow, (3) suprasternal aortic Doppler, (4) bioreactance, (5) plethysmography with digital vascular unloading method, and (6) inferior vena cava collapsibility index.

Methods: This is a prospective observational study of non-invasive methods of assessing fluid responsiveness in the ED. Participants were non-ventilated ED adult patients requiring intravenous fluid resuscitation. Feasibility of each method was determined by the proportion of clinically interpretable measurements from the number of measurement attempts. Repeatability was determined by comparing the mean difference of two paired measurements in a fluid steady state (after participants received an intravenous fluid bolus).

Results: 76 patients were recruited in the study. A total of 207 fluid responsiveness measurement sets were analysed. Feasibility rates were $97.6 \%$ for bioreactance, $91.3 \%$ for vascular unloading method with plethysmography, $87.4 \%$ for common carotid artery blood flow, $84.1 \%$ for inferior vena cava collapsibility index, 78.7\% for LVOT VTI, and 76.8\% for suprasternal aortic Doppler. The feasibility rates difference between bioreactance and all other methods was statistically significant.

Conclusion: Our study shows that non-invasive fluid responsiveness monitoring in the emergency department may be feasible with selected methods. Higher repeatability of measurements were observed in non-ultrasound methods. These findings have implications for further studies specifically assessing the accuracy of such non-invasive cardiac output methods and their effect on patient outcome in the ED in fluid depleted states such as sepsis.
\end{abstract}

Keywords: Fluid responsiveness, Stroke volume, Ultrasound, Bioreactance, Plethysmography, Sepsis

\section{Background}

Intravenous fluid therapy aims to improve cardiac output and therefore restore oxygen delivery to hypoperfused organs. However, iatrogenic tissue oedema may occur when too much intravenous fluid is given. This is associated with increased mortality, renal failure and respiratory compromise [1-3]. Fluid resuscitation in the ED is most commonly guided by physiological parameters (heart rate,

\footnotetext{
* Correspondence: david.mcgregor@barsthealth.nhs.uk

${ }^{1}$ Queen Mary University London and Barts Health NHS Trust, London, UK

Full list of author information is available at the end of the article
}

blood pressure, capillary refill time) and/or biochemical parameters $(\mathrm{pH}$, lactate and metabolic acidosis), but which are neither sensitive or specific for tissue perfusion [4-7].

Fluid responsiveness is commonly defined as a stroke volume increase of at least $10 \%$ following a fluid bolus of 200-500mls $10-15 \mathrm{~min}$ [8]. Targeting intravenous fluid therapy to fluid responsiveness and fluid tolerance, and therefore stroke volume/cardiac output, may optimise tissue oxygenation and reduce the risk of tissue oedema. In the intensive care setting, fluid resuscitation is frequently guided by invasive monitoring of cardiac output, previously with Pulmonary Artery Catheterisation (PAC), and now 
commonly with less invasive devices, such as arterial pulse pressure analysis or oesophageal Doppler [9]. However, these methods are invasive and unsuitable for routine monitoring in the Emergency Department $[10,11]$.

Non-invasive cardiac output monitoring methods which can rapidly identify fluid responsiveness and guide fluid therapy are emerging in the ED and in the pre-hospital environment $[12,13]$. These methods include left ventricular outflow tract velocity time integral (LVOT VTI) [14, 15], common carotid artery blood flow monitoring (CCABF) [16], suprasternal aortic Doppler (SSAD) [17, 18], plethysmography using the vascular unloading technique (PVUT) $[19,20]$, and thoracic bioreactance [21-23]. Inferior vena cava collapsibility index (IVCCI), while not measuring cardiac output, may be an indicator of fluid responsiveness [23-25].

The range of methods available can be confusing to ED practitioners given the absence of systematic comparison. Assessing the clinical value of a diagnostic test is a multi-phase process which includes assessing its feasibility, repeatability, accuracy, impact on patient outcomes, and cost. The objectives of this study were to systematically compare methods for a broad range of ED patients according to two key diagnostic criteria:

1. Feasibility defined as the proportion of clinically interpretable results yielded from attempted measurements, and

2. Repeatability (or test-retest reliability) defined as the mean difference occurring with repeated measurements of the same target as a marker of internal validity.

\section{Methods}

\section{Study protocol}

The study was a prospective observational study. A predefined point score system was used for each technique to sort clinically interpretable measurements from uninterpretable measurements. Feasibility was determined by dividing the number of clinically interpretable measurements by the total number of attempted measurements for each method. Repeatability was determined by comparing the mean difference of two paired measurements in a fluid steady (replete) state for each method (post-fluid measurement rounds, M2 and M3). Participants were placed in a semi-recumbent position at 30 degrees on a trolley. The stroke volume was simultaneously measured by LVOT VTI, CCABF, bioreactance, and PVUT (measurement round 1 - M1). IVCCI was also measured. A $250-500 \mathrm{mls}$ of crystalloid fluid bolus was then delivered over $15 \mathrm{~min}$. A post-fluid measurement round with all six methods was then conducted (M2), immediately followed by a third measurement round (M3) to assess repeatability (Fig. 1). The duration for each measurement was recorded. Ultrasound measurements were saved as

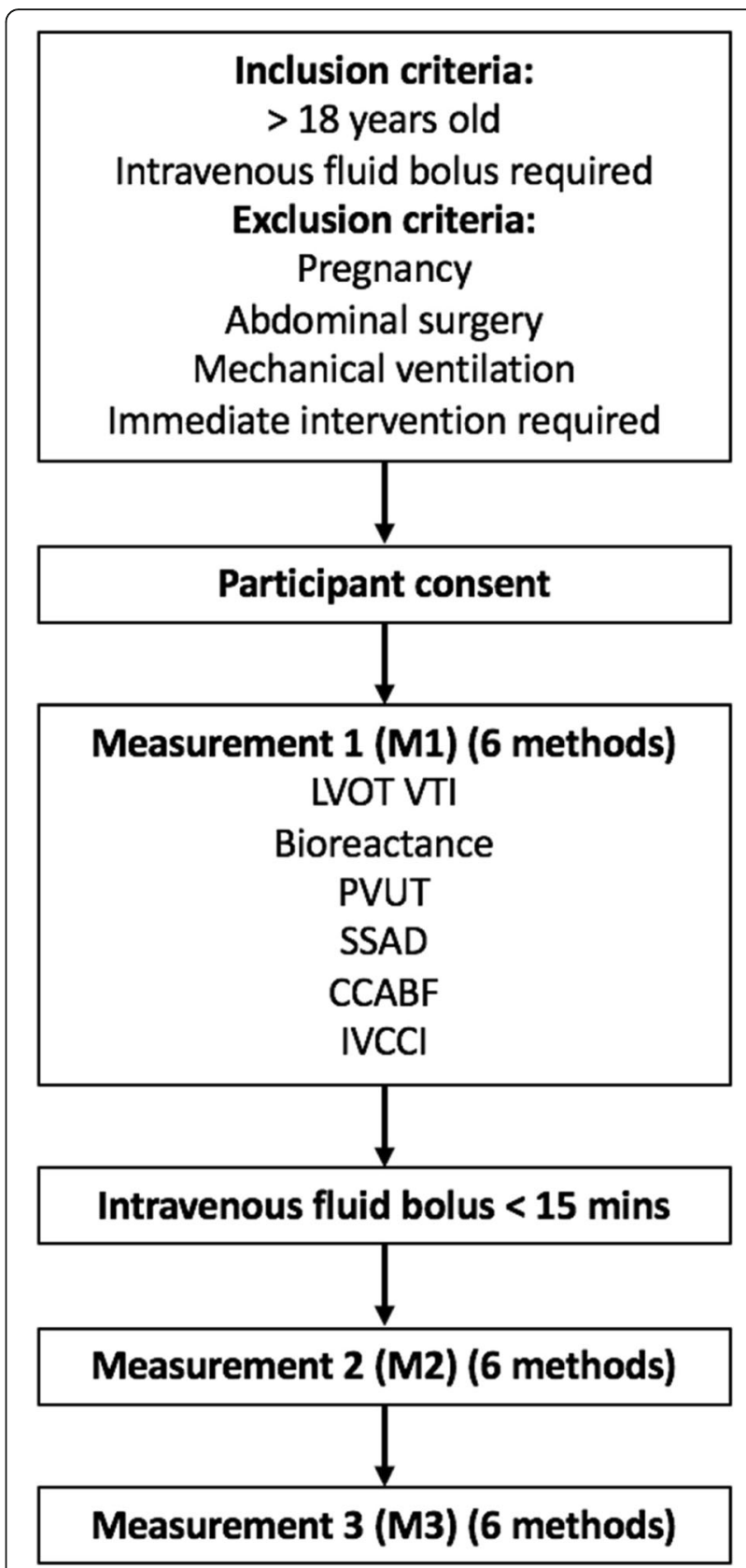

Fig. 1 Study participant pathway. SV = stroke volume; $C O=$ cardiac output; PVUT = plethysmography vascular unloading technique; $\mathrm{CCABF}=$ common carotid artery blood flow; IVCCI = inferior vena cava collapsibility index; LVOT VTI = left ventricular outflow tract velocity time integral; SSAD = suprasternal aortic Doppler

screenshots and scored for clinical interpretability by a blinded operator according to a pre-defined pragmatic dichotomous outcome: clinically interpretable versus clinically uninterpretable (Fig. 2). Dinh et al's method [26] was used to measure stroke volume by LVOT VTI. Stolz et al's method was used to measure CCABF [27]. The Fremantle criteria [28] were used to measure stroke volume by SSAD. IVCCI was measured in $\mathrm{B}$ mode with the minimal and 


\begin{tabular}{|l|c|}
\hline LVOT VTI & Score \\
\hline $\begin{array}{l}\text { Clear apical 5-chamber view with proper alignment of } \\
\text { the pulse Doppler sample volume parallel to the aortic } \\
\text { flow with minimal spectral broadening. }\end{array}$ & \\
\hline $\begin{array}{l}\text { Pulse Doppler sample volume not completely parallel } \\
\text { to flow but within } 20^{\circ}-30^{\circ} \text { or with excessive spectral } \\
\text { broadening. }\end{array}$ & \\
\hline $\begin{array}{l}\text { Completely unobtainable images of apical 5-chamber } \\
\text { view or extremely large pulsed-wave Doppler angle to } \\
\text { flow. }\end{array}$ & Inadequate \\
\hline $\begin{array}{l}\text { Optimal or suboptimal score = clinically interpretable } \\
\text { Inadequate = clinically uninterpretable }\end{array}$
\end{tabular}

\begin{tabular}{|l|c|}
\hline CCABF & Score \\
\hline Measurement of diameter obtained in systole & 1 \\
\hline Diameter measured 1-2cm proximal to carotid bulb & 1 \\
\hline Diameter measured from intima to intima & 1 \\
\hline Doppler gate placed at the centre of the CCA & 1 \\
\hline Doppler gates parallel to CCA walls & 1 \\
\hline Well-defined spectral waveform obtained & 1 \\
\hline
\end{tabular}

Score $\geq 4$ = clinically interpretable

Score $<4=$ clinically uninterpretable

\begin{tabular}{|l|c|}
\hline SSAD & Score \\
\hline Well-defined image base & 1 \\
\hline Well-defined image peak & 1 \\
\hline Well-defined commencement of flow or heart sound & 1 \\
\hline Well-defined cessation of flow or heart sound & 1 \\
\hline Appropriate scale used on screen & 1 \\
\hline Minimal acoustic interference & 1 \\
\hline
\end{tabular}

Score $\geq 4$ = clinically interpretable

Score $<4=$ clinically uninterpretable

\begin{tabular}{|l|c|}
\hline IVCCI & Score \\
\hline Smallest IVC diameter obtained during inspiration & 1 \\
\hline Largest IVC diameter obtained during expiration & 1 \\
\hline $\begin{array}{l}\text { Diameter measured within 1cm of hepatico-caval } \\
\text { junction of 2-3 cm of atrial-caval junction }\end{array}$ & 1 \\
\hline Diameter measured from intima to intima & 1 \\
\hline
\end{tabular}

Score $\geq 3$ = clinically interpretable

Score $<3=$ clinically uninterpretable

Fig. 2 Quality assessment criteria for LVOT VTI, CCABF, SSAD and IVCCI

maximal IVC diameters during respiration measured $1 \mathrm{~cm}$ distal to the hepatic-caval junction or $2-3 \mathrm{~cm}$ distal to the atrial-caval junction as guided by previous studies $[24,25$, $29,30]$. IVCCI was calculated with the following formula:

$$
\frac{I V C \text { diameter (expiration)-IVC diameter (inspiration) }}{I V C \text { diameter (expiration) }}
$$

Stroke volume by PVUT and bioreactance was measured following the manufacturer's instructions. Stroke volume is displayed onto an external monitor for both methods. Feasibility was the proportion of readings displayed as a proportion of all attempted readings one minute prior to starting the fluid bolus and within five minutes of the fluid bolus ending. If no values for stroke volume was displayed during these periods a failed attempt was recorded.

\section{Participants}

Potential participants were screened for inclusion and exclusion criteria by the department clinical team only 
on arrival to the ED to avoid selection bias. All eligible patients were then referred to the research team for consent. The inclusion criteria were: older than 18 years of age and necessitating an intravenous fluid bolus of $250-500 \mathrm{mls}$ as assessed by the clinical care team. The exclusion criteria were: pregnancy, recent abdominal surgery (potential for anatomical alteration), invasive or non-invasive mechanical ventilation, and presentations requiring immediate intervention (systolic blood pressure $<80 \mathrm{mmHg}$ including traumatic or cardiogenic shock, and ventricular or supraventricular tachycardia). All patients attending the ED during the study period during the hours of 09:00 to 20:00 Monday to Friday between August to October 2015 were eligible for recruitment. Patients having received fluids in a pre-hospital setting were not excluded from the study.

\section{Equipment}

LVOT VTI was measured with a uSmart 3300 ultrasound system (Terason, Burlington, MA, USA). Carotid Doppler traces were assessed by a Sonosite EDGE (Sonosite, Bothwell, WA, USA). Suprasternal aortic Doppler traces were obtained using the USCOM-1A (Pty Ltd., Coffs Harbour, NSW, Australia). PVUT was assessed with a LiDCO continuous non-invasive arterial pressure device (LiDCO plus and CNAP, LiDCO Ltd., London, UK).
Bioreactance was assessed with a Cheetah Medical device (Cheetah Medical, Portland, OR, USA).

\section{Operator training}

A review of the literature showed that without prior experience performing LVOT VTI at a competent level takes $40-50$ practice studies [31], CCABF requires 20-25 studies [27], SSAD requires 20-40 studies [18, 28, 32, 33] and IVCCI requires 50 studies [34, 35]. Three operators (DM, SG, SS) with no prior ultrasound experience were trained to operate all six non-invasive monitoring methods during the same pre-study training programme. The programme consisted of the standard UK Level 1 ultrasound course followed by 50 measurements for all four ultrasound methods on volunteers. Bioreactance and PVUT training was provided by the respective manufacturers for $2 \mathrm{~h}$ each. This pragmatic training programme ensured that operators' performance and experience on all methods was identical and achievable by junior residents and ED nurses. No intra-operator or inter-operator variability assessment was performed.

\section{Statistical analysis}

Measurement data were collected onto a REDCap database (Vanderbilt University, Nashville, TN, USA) and

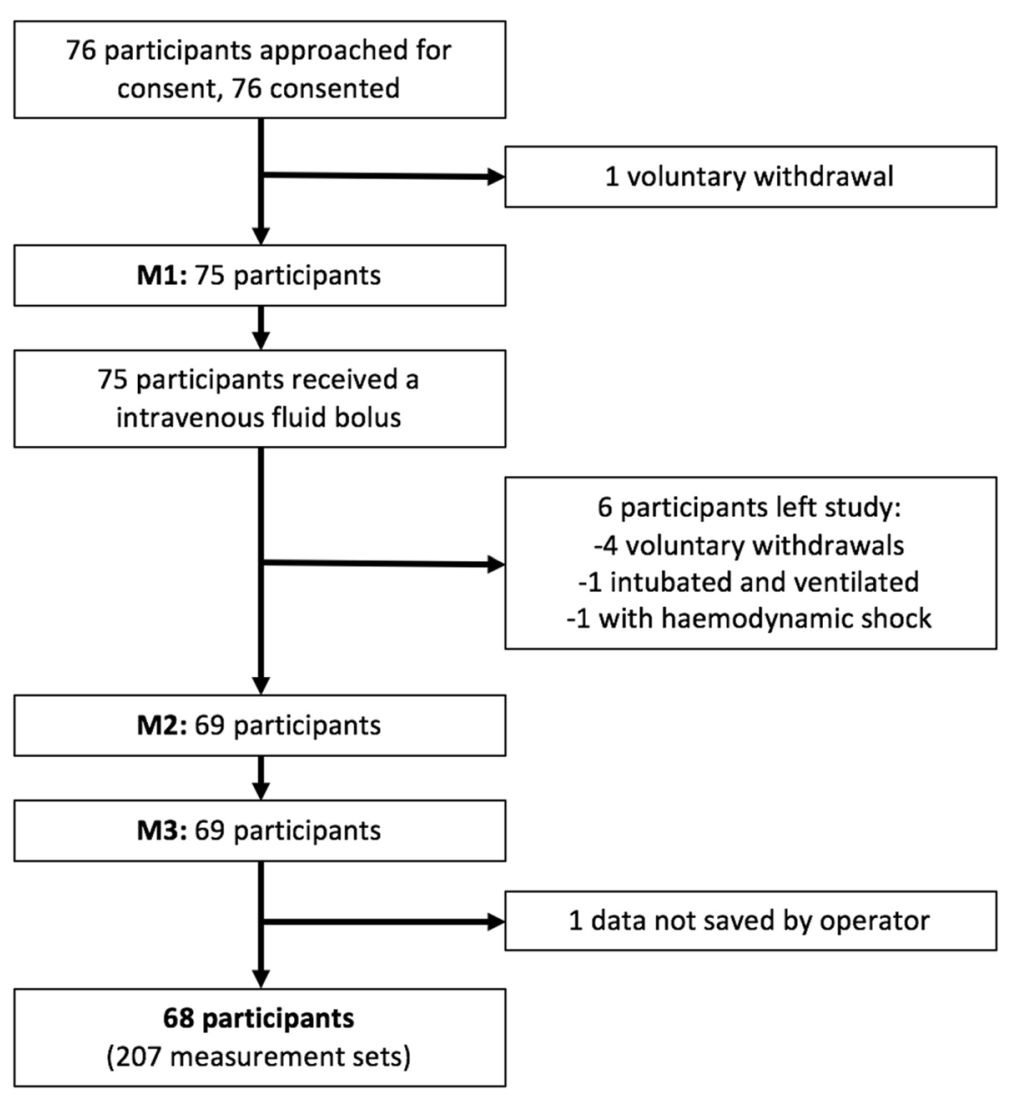

Fig. 3 Collection of results 
analysed with SPSS v24 (IBM, New York City, NY, USA). $P<0.05$ (two-tailed) was considered statistically significant. 38 participants with a minimum of 2 rounds of measurements each was the required sample size using a previously described power calculation [36]. Descriptive data are presented with means and 95\% confidence intervals and medians with inter-quartile ranges as appropriate. Cochran's Q test with a Bonferroni correction was used to compare feasibility between methods. Limits of agreement (LoA) analysis was used to assess repeatability as previously described [37]. One-sample $t$-test was used to verify if the difference between paired measurements (M2 and M3) varied significantly from zero. Bland-Altman analysis was performed to compare paired measurements [38]. Linear regression was used to identify the presence of proportional bias through the range of paired measurements.

\section{Ethics, consent and permissions}

This study was approved by the East of England Research Ethics Committee (REC reference 15/EE/0227; IRAS project ID 172012). Informed consent by each subject was required for participation in this study.

\section{Results}

76 participants were recruited in the study including 68 who completed the study protocol (5 voluntary withdrawals, 1 developed signs of shock, 1 was intubated and ventilated, 1 accidental data loss during data transfer) (Fig. 3). Participant characteristics are shown in Table 1.

\section{Feasibility}

Feasibility for the six methods in decreasing order were bioreactance with a completion proportion of $97.6 \%$ (202 clinically interpretable results out of 207 attempts; 95\% CI: 95.4-99.6\%), PVUT with 91.3\% (189 clinically interpretable results out of 207 attempts; 95\% CI: 87.4-95.1\%), CCABF with $87.4 \%$ (181 clinically interpretable results out of 207 attempts; 95\% CI: 82.9-91.9\%), IVCCI with 84.1\% (174 clinically interpretable results out of 207 attempts; 95\% CI: 79.0-89.0\%), LVOT VTI with 78.7\% (163 clinically interpretable results out of 207 attempts; 95\% CI: 73.1-84.3\%) and SSAD with 76.8\% (159 clinically interpretable results out of 207 attempts; 95\% CI: 71.0-82.5\%) (Additional file 1: Fig. S4). Bioreactance had statistically significant superior feasibility to all other methods except PVUT. PVUT was superior to LVOT and SSAD. All other methods were found to have comparable feasibility. Median time to obtaining the first stroke volume measurement (M1) were found to be 0:57 (min:sec) for SSAD, 01:34 for IVCCI, 02:09 for LVOT VTI, 02:26 for CCABF, 07:02 for bioreactance and 08:35 for PVUT (Fig. 4).
Table 1 Participant baseline characteristics

\begin{tabular}{|c|c|}
\hline & Participants $(n=76)$ \\
\hline Age & $52.5(21.7)$ \\
\hline $\operatorname{Sex}(F: M)$ & $38: 38$ \\
\hline Body mass index & $25.8(6)$ \\
\hline MAP & $89.9(16.8)$ \\
\hline SBP & $122.5(22.5)$ \\
\hline DBP & $69.8(16)$ \\
\hline Heart rate & $94.8(19.4)$ \\
\hline Fluid bolus (FB) & $373.3(259.1)$ \\
\hline Duration of FB & $12.2(9.9)$ \\
\hline Initial lactate & $4.74(8.85)$ \\
\hline Previous fluid & $390.9(572.9)$ \\
\hline Treated for sepsis (Y:N) & 40:36 \\
\hline \multicolumn{2}{|l|}{ ED diagnoses* } \\
\hline Sepsis & 40 \\
\hline Unknown source at presentation & 14 \\
\hline Respiratory tract & 9 \\
\hline Urinary tract & 8 \\
\hline Gastro-intestinal tract & 3 \\
\hline Post-operative & 3 \\
\hline Cellulitis & 1 \\
\hline Dental abscess & 1 \\
\hline Neutropenic sepsis & 1 \\
\hline Other & 36 \\
\hline Non-specifically unwell & 13 \\
\hline Intoxication drugs/alcohol & 4 \\
\hline Syncope & 4 \\
\hline Viral gastroenteritis & 4 \\
\hline Atrial fibrillation > $130 \mathrm{BPM}$ & 2 \\
\hline Vestibular neuritis & 2 \\
\hline Exacerbation of Crohn's disease & 1 \\
\hline Hyperglycaemic state & 1 \\
\hline Ischaemic limb & 1 \\
\hline Pulmonary embolism & 1 \\
\hline Seizure & 1 \\
\hline Renal colic (vomiting) & 1 \\
\hline Biliary colic (vomiting) & 1 \\
\hline
\end{tabular}

*preliminary diagnosis after initial ED assessment; standard deviations are denoted in brackets, MAP mean arterial pressure, SBP systolic blood pressure, $D B P$ diastolic blood pressure, $E D$ emergency department)

\section{Repeatability}

No significant difference was found between post-fluid paired measurements for all six methods (M2 and M3). In other words, after participants received fluids, differences in measurements for M2 and M3 did not significantly vary from zero for each method. Linear regression analysis 


\begin{tabular}{|l|c|c|c|c|c|c|}
\hline & Bioreactance & PVUT & CCABF & IVCCI & LVOT VTI & SSAD \\
\hline $\begin{array}{l}\text { No } \\
\text { measurement } \\
\text { feasible (\%) }\end{array}$ & $1(1.4)$ & $4(5.8)$ & $5(7.3)$ & $8(11.7)$ & $12(17.6)$ & $14(20.5)$ \\
$\begin{array}{l}\geq 1 \\
\text { measurement(s) } \\
\text { not feasible (\%) }\end{array}$ & $2(3)$ & $5(7.4)$ & $8(11.8)$ & $9(13.3)$ & $5(7.4)$ & $5(7.4)$ \\
\hline $\begin{array}{l}\text { All } \\
\text { measurements } \\
\text { feasible (\%) }\end{array}$ & $65(95.6)$ & $59(86.8)$ & $55(80.9)$ & $51(75)$ & $51(75)$ & $49(72.1)$ \\
\hline
\end{tabular}

Fig. 4 Mean time to completion of M1 for each method (minutes)

showed the absence of proportional bias (Additional file 2: Table S2). Bland-Altman plots were traced to define the limits of agreement between paired M2 and M3 measurements (Fig. 5). Clinically acceptable limits of agreement were traced to within $+/-10 \%$ of the mean of paired measurements (blue area in Bland Altman plots).

\section{Discussion}

This study shows that the feasibility for assessing fluid responsiveness non-invasively in the ED was greater than $75 \%$ for all methods but with significant differences observed between methods. Operator-independent methods (bioreactance and PVUT) showed higher feasibility rates over ultrasound methods. This can be explained by the former requiring less cooperation on part of at times agitated and confused patients and therefore more successful in obtaining measurements. The high feasibility of bioreactance has been reported in trauma patients [39, 40]. PVUT showed significantly higher feasibility than LVOT and SSAD but not CCABF or IVCCI.

The results also illustrate the impact that patient anatomy, care setting and operator skill may have on feasibility for ultrasound methods. For IVCCI, previous studies have reported feasibility rates of 85 to $93 \%$ stating notably that adipose tissue and bowel gas can interfere with IVC visualisation [41]. Similarly, in the hands of expert sonographers in ICU, LVOT VTI feasibility ranges from 60 to $100 \%$ [42]. However, in ED patients, Dinh et al. found that two ED physicians with $20 \mathrm{~h}$ of hands-on instruction obtained a feasibility rate of $78.4 \%$ [26], similar to was observed in our cohort of participants. For SSAD, previous studies have reported that tracheostomies, short necks,

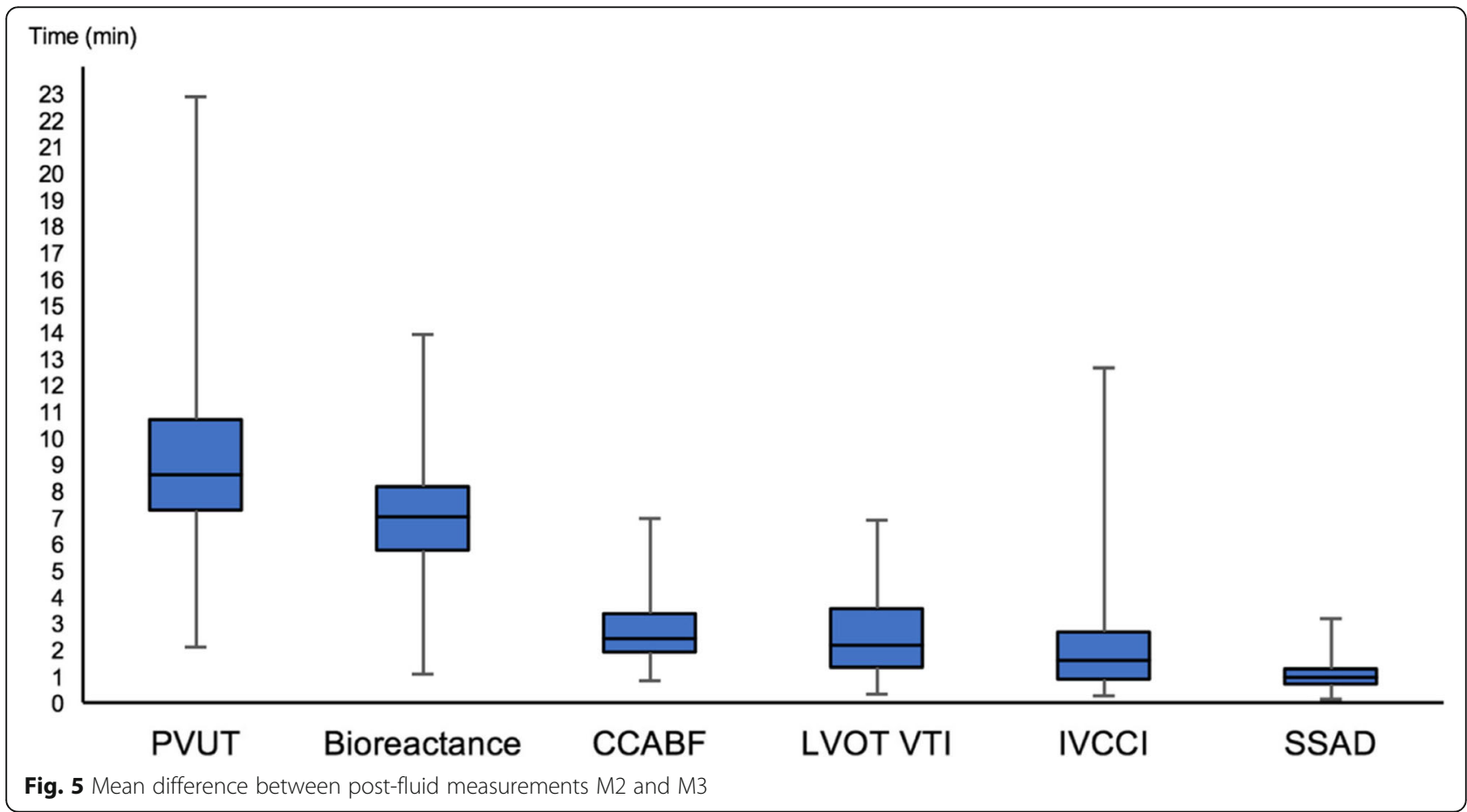


and thick sternums can limit feasibility with rates of 77 and $87 \%$ cited in ICU and ED patients respectively [43, 44]. For CCABF, calcified arterial plaques and cervical arthritis have been described as limiting patient factors [45]. In this study however, CCABF achieved a feasibility rate of $87.4 \%$, the highest among ultrasound methods but without achieving statistical significance.

The absence of standardised measurement technique for IVCCI and CCABF is a concern. A review of IVCCI shows that eight different measurement techniques were used in ten separate diagnostic studies [24, 25, 41, 46-52]. A consensus on standardised technique should be agreed with ED patients in mind; such an approach would ensure continuity of monitoring from arrival and throughput the patient journey in the hospital.

With regards to obtaining a first reading (M1), all ultrasound methods had a median measurement time of under 2 min $30 \mathrm{~s}$ (Fig. 4). By contrast, bioreactance and PVUT had median measurement times of over $7 \mathrm{~min}$ due to calibration sequences. Inadvertent finger motion by less cooperative participants was found to interfere with PVUT calibration. In one case, a measurement time of $22 \mathrm{~min} 52 \mathrm{~s}$ to obtaining the first reading was recorded. Once calibrated however PVUT and bioreactance both provide continuous cardiac output monitoring.

If feasibility is an essential aspect of clinical value, repeatability informs on the internal validity of the method and therefore the actual quality of the data obtained. This study found no statistically significant differences between the post-fluid paired measurements (M2 and M3) for all methods; each method was therefore able to consistently provide comparable repeat readings in the $95 \%$ limits of agreement. To verify if the fluid responsiveness threshold was crossed on paired measurements in a presumably fluid-steady state we applied limits of agreement of +/$10 \%$ to the paired measurement mean. We found that CCABF and IVCCI showed least agreement with most paired readings falling outside these limits. This has important implications. It is likely that operators may require more than 50 scans of baseline experience on CCABF and IVCCI to achieve intra-operator variability of less than $10 \%$ to correctly identify fluid responsive states with those methods. It also possible that these methods may also have lower intrinsic repeatability.

\section{Study limitations}

Firstly, it is likely that the absolute feasibility of each technique would be higher if it had been assessed on its own. The higher rates of feasibility generally observed in ICU studies and the longer measurement times seem to support this. This should not affect the relative feasibility between methods. Secondly, repeatability of each method was assessed by paired readings of a fluid steady state (M2 versus M3) rather than paired readings of a fluid dynamic state (change from M1 to M2 versus change from M1bis to M2bis). This was the preferred approach in view of the time available for measurements. Thirdly, not all participants may have reached a fluid steady state after receiving a fluid bolus of 250-500mls. However, such volume was felt suitable to reverse at least partially fluid depletion in eligible patients.

\section{Conclusions}

The findings of this prospective observational have important implications in helping select suitable method to assess fluid responsiveness in fluid depleted spontaneously breathing ED patients, including septic patients. In our cohort of participants operator-independent methods such as bioreactance and PVUT had high feasibility rates than ultrasound-based methods. The value of such methods should next be compared on their accuracy in identifying fluid responders and their impact on patient outcomes.

\section{Additional files}

Additional file 1: Figure S4. Percentage feasibility for non-invasive cardiac output monitoring methods by participant $(n=68)$. Figure illustrating the percentage feasibility for non-invasive cardiac output monitoring methods by participant. (DOCX $132 \mathrm{~kb}$ )

Additional file 2: Table S2. Proportional bias analysis using linear regression analysis. Table detailing linear regression analysis. (DOCX 13 $\mathrm{kb})$

\section{Abbreviations}

CCA: Common carotid artery; CCABF: Common carotid arterial blood flow; CNAP: Continuous non-invasive arterial pressure; ED: Emergency department; ICU: Intensive Care Units; IVC: Inferior vena cava; IVCCI: Inferior vena cava collapsibility index; LVOT VTI: Left ventricular outflow tract velocity time integral; PVUT: Plethysmography with vascular unloading technique; SBP: Systolic blood pressure; SSAD: Suprasternal aortic Doppler;

USCOM: Ultrasound cardiac output monitor

\section{Acknowledgements}

We would like to thank all the participants and their families. Thanks to nursing and medical staff at the Royal London Hospital Emergency Department. Special thanks to Jason Pott and Fiona Bennin for their support.

\section{Funding}

The study was funded by the Royal College of Emergency Medicine. For the duration of the study, the research team received equipment from: Terason (Burlington, MA, USA): 1 uSmart 3300 ultrasound system. Pty Ltd. (Coffs Harbour, NSW, Australia): 1 USCOM-1A system. LiDCO Ltd. (London, UK): 1 LiDCO+ and CNAP system.

Cheetah Medical (Portland, OR, USA): 1 Cheetah Medical system

\section{Availability of data and materials}

The datasets used and/or analysed during the current study are available from the corresponding author on reasonable request.

\section{Authors' contributions}

DM was principal investigator and compiled the final manuscript. SS, SG, and SA collected, entered and analysed clinical data. TG provided statistical analysis of the data. TH was chief investigator, designed the study protocol and provided quality assurance. All authors read and approved the final manuscript.

Ethics approval and consent to participate

This study was approved by the NRES Committee East of England - Essex. 
Study reference 15/EE/0227

\section{Consent for publication}

All participants consented for study data to be published

\section{Competing interests}

The authors declare that they have no competing interests.

\section{Publisher's Note}

Springer Nature remains neutral with regard to jurisdictional claims in published maps and institutional affiliations.

\section{Author details}

'Queen Mary University London and Barts Health NHS Trust, London, UK. ${ }^{2}$ University of Western Australia School of Medicine and Pharmacology, Perth, Australia. ${ }^{3}$ Emergency Department Research Group, Royal London Hospital, London, UK. ${ }^{4}$ Faculty of Epidemiology and Population Health, London School of Hygiene and Tropical Medicine, London, UK. ${ }^{5}$ Emergency Medicine, Queen Mary University London and Barts Health NHS Trust, London, UK.

\section{Received: 31 July 2018 Accepted: 4 January 2019}

Published online: 11 March 2019

\section{References}

1. Alsous F, Khamiees M, DeGirolamo A, Amoateng-Adjepong Y, Manthous CA. Negative fluid balance predicts survival in patients with septic shock: a retrospective pilot study. Chest. 2000;117:1749-54.

2. Boyd JH, Forbes J, Nakada TA, Walley KR, Russell JA. Fluid resuscitation in septic shock: a positive fluid balance and elevated central venous pressure are associated with increased mortality. Crit Care Med. 2011;39:259-65.

3. Murphy CV, Schramm GE, Doherty JA, Reichley RM, Gajic O, Afessa B, Micek $\mathrm{ST}$, Kollef $\mathrm{MH}$. The importance of fluid management in acute lung injury secondary to septic shock. Chest. 2009;136:102-9.

4. McGee S, Wr A, Simel D. The rational clinical examination. Is this patient hypovolemic? JAMA. 1999;281:1022-9.

5. Fortes MB, Owen JA, Raymond-Barker P, Bishop C, Elghenzai S, Oliver SJ, Walsh NP. Is this elderly patient dehydrated? Diagnostic accuracy of hydration assessment using physical signs, urine, and saliva markers. J Am Med Dir Assoc. 2015;16:221-8.

6. Nowak RM, Sen A, Garcia AJ, Wilkie H, Yang JJ, Nowak MR, Moyer ML. The inability of emergency physicians to adequately clinically estimate the underlying hemodynamic profiles of acutely ill patients. Am J Emerg Med. 2012;30:954-60.

7. Maurer C, Wagner JY, Schmid RM, Saugel B. Assessment of volume status and fluid responsiveness in the emergency department: a systematic approach. Med Klin Intensivmed Notfmed. 2017;112:326-33.

8. Marik PE. Fluid responsiveness and the six guiding principles of fluid resuscitation. Crit Care Med. 2016:44:1920-2.

9. Pugsley J, Lerner AB. Cardiac output monitoring: is there a gold standard and how do the newer technologies compare? Semin Cardiothorac Vasc Anesth. 2010;14:274-82.

10. Harvey S, Harrison DA, Singer M, Ashcroft J, Jones CM, Elbourne D, Brampton W, Williams D, Young D, Rowan K. Assessment of the clinical effectiveness of pulmonary artery catheters in management of patients in intensive care (PACman): a randomised controlled trial. Lancet. 2005;366:472-7.

11. Binanay C, Califf RM, Hasselblad V, O'Connor CM, Shah MR, Sopko G, Stevenson LW, Francis GS, Leier CV, Miller LW. Evaluation study of congestive heart failure and pulmonary artery catheterization effectiveness: the ESCAPE trial. Jama. 2005;294:1625-33.

12. Laher AE, Watermeyer MJ, Buchanan SK, Dippenaar N, Simo NC, Motara F, Moolla M. A review of hemodynamic monitoring techniques, methods and devices for the emergency physician. Am J Emerg Med. 2017.

13. Hou PC, Filbin MR, Napoli A, Feldman J, Pang PS, Sankoff J, Lo BM, DickeyWhite H, Birkhahn RH, Shapiro NI. Cardiac output monitoring managing intravenous therapy (COMMIT) to treat emergency department patients with Sepsis. Shock. 2016:46:132-8.

14. Dittmann H, Voelker W, Karsch KR, Seipel L. Influence of sampling site and flow area on cardiac output measurements by Doppler echocardiography. J Am Coll Cardiol. 1987;10:818-23.
15. Seo H, Yamagishi M, Haque SA, Mohibullah AK, Aa-S M, Nakatani S, Kwan OL, DeMaria AN, Miyatake K. An enhanced method for measuring cardiac output using Doppler color flow echocardiography. Jpn Circ J. 1997;61:90511.

16. Marik PE, Levitov A, Young A, Andrews L. The use of bioreactance and carotid Doppler to determine volume responsiveness and blood flow redistribution following passive leg raising in hemodynamically unstable patients. Chest. 2013;143:364-70.

17. Horster S, Stemmler HJ, Strecker N, Brettner F, Hausmann A, Cnossen J, Parhofer KG, Nickel T, Geiger S. Cardiac output measurements in septic patients: comparing the accuracy of USCOM to PiCCO. Crit Care Res Pract. 2012;2012:270631

18. van Lelyveld-Haas LE, van Zanten AR, Borm GF, Tjan DH. Clinical validation of the non-invasive cardiac output monitor USCOM-1A in critically ill patients. Eur J Anaesthesiol. 2008;25:917-24.

19. Hahn R, Rinosl H, Neuner M, Kettner SC. Clinical validation of a continuous non-invasive haemodynamic monitor (CNAP ${ }^{\text {TM }} 500$ ) during general anaesthesia. Br J Anaesth. 2012;108:581-5.

20. Nies C, Bauer M, Berg P, Rosenberg J, Hedderich J, Bein B, Hinz J, Hanss R. Investigation of the agreement of a continuous non-invasive arterial pressure device in comparison with invasive radial artery measurement. $\mathrm{Br} \mathrm{J}$ Anaesth. 2012;108:202-10.

21. Raval NY, Squara P, Cleman M, Yalamanchili K, Winklmaier M, Burkhoff D. Multicenter evaluation of noninvasive cardiac output measurement by bioreactance technique. J Clin Monit Comput. 2008:22:113-9.

22. Squara P, Rotcajg D, Denjean D, Estagnasie P, Brusset A. Comparison of monitoring performance of bioreactance vs. pulse contour during lung recruitment maneuvers. Crit Care. 2009;13:R125.

23. Zhang Z, Xu X, Ye S, Xu L. Ultrasonographic measurement of the respiratory variation in the inferior vena cava diameter is predictive of fluid responsiveness in critically ill patients: systematic review and meta-analysis. Ultrasound Med Biol. 2014.

24. Lanspa MJ, Grissom CK, Hirshberg EL, Jones JP, Brown SM. Applying dynamic parameters to predict hemodynamic response to volume expansion in spontaneously breathing patients with septic shock. Shock. 2013:39:155-60

25. Muller L, Bobbia X, Toumi M, Louart G, Molinari N, Ragonnet B, Quintard H, Leone $M$, Zoric L, Lefrant JY. Respiratory variations of inferior vena cava diameter to predict fluid responsiveness in spontaneously breathing patients with acute circulatory failure: need for a cautious use. Crit Care. 2012;16.

26. Dinh VA, Ko HS, Rao R, Bansal RC, Smith DD, Kim TE, Nguyen HB. Measuring cardiac index with a focused cardiac ultrasound examination in the ED. Am J Emerg Med. 2012;30:1845-51.

27. Stolz LA, Mosier JM, Gross AM, Douglas MJ, Blaivas M, Adhikari S. Can emergency physicians perform common carotid Doppler flow measurements to assess volume responsiveness? West J Emerg Med. 2015;16:255-9.

28. Dey I, Sprivulis P. Emergency physicians can reliably assess emergency department patient cardiac output using the USCOM continuous wave Doppler cardiac output monitor. Emerg Med Australas. 2005;17:193-9.

29. Akkaya A, Yesilaras M, Aksay E, Sever M, Atilla OD. The interrater reliability of ultrasound imaging of the inferior vena cava performed by emergency residents. Am J Emerg Med. 2013;31:1509-11.

30. De Lorenzo RA, Holbrook-Emmons VL. Ultrasound measurement of inferior vena cava diameters by emergency department nurses. Adv Emerg Nurs J. 2014;36:271-8.

31. Royse CF, Seah $J$, Donelan $L$, Royse AG. Point of care ultrasound for basic haemodynamic assessment: novice compared with an expert operator. Anaesthesia. 2006;61:849-55.

32. Siu L, Tucker A, Manikappa SK, Monagle J. Does patient position influence Doppler signal quality from the USCOM ultrasonic cardiac output monitor? Anesth Analg. 2008;106:1798-802.

33. Duchateau FX, Gauss T, Burnod A, Ricard-Hibon A, Juvin P, Mantz J. Feasibility of cardiac output estimation by ultrasonic cardiac output monitoring in the prehospital setting. Eur J Emerg Med. 2011;18:357-9.

34. ACEP. American College of Emergency Medicine: emergency ultrasound guidelines-2001. Ann Emerg Med. 2001;38:470-81.

35. ACEP. American College of Emergency Medicine: emergency ultrasound guidelines-2009. Ann Emerg Med. 2009;53:550-70.

36. Gore S, Altman D. How large a sample. In: Statistics in Practice. London: BMJ Publishing; 2001. Volume 6-8. 
37. Bland JM, Altman DG. Statistical methods for assessing agreement between two methods of clinical measurement. Lancet. 1986;1:307-10.

38. Bland JM, Altman DG. Measuring agreement in method comparison studies. Stat Methods Med Res. 1999:8:135-60.

39. Dunham CM, Chirichella TJ, Gruber BS, Ferrari JP, Martin JA, Luchs BA, Hileman BM, Merrell R. Emergency department noninvasive (NICOM) cardiac outputs are associated with trauma activation, patient injury severity and host conditions and mortality. J Trauma Acute Care Surg. 2012;73:479-85.

40. Dubost C, Sauvet F, Evans D, Dusonchet S, Pelletier C, Rousseau JM, Coste S. Feasibility of noninvasive hemodynamic monitoring by bioreactance for airevacuated casualties. J Trauma Acute Care Surg. 2013;74:1146-50.

41. Resnick J, Cydulka R, Platz E, Jones R. Ultrasound does not detect early blood loss in healthy volunteers donating blood. J Emerg Med. 2011;41:270-5.

42. Preau S, Saulnier F, Dewavrin F, Durocher A, Chagnon JL. Passive leg raising is predictive of fluid responsiveness in spontaneously breathing patients with severe sepsis or acute pancreatitis. Crit Care Med. 2010;38:819-25.

43. Corley A, Barnett AG, Mullany D, Fraser JF. Nurse-determined assessment of cardiac output. Comparing a non-invasive cardiac output device and pulmonary artery catheter: a prospective observational study. Int I Nurs Stud. 2009;46:1291-7.

44. Nguyen HB, Losey T, Rasmussen J, Oliver R, Guptill M, Wittlake WA, Corbett SW. Interrater reliability of cardiac output measurements by transcutaneous Doppler ultrasound: implications for noninvasive hemodynamic monitoring in the ED. Am J Emerg Med. 2006;24:828-35.

45. Gassner M, Killu K, Bauman Z, Coba V, Rosso K, Blyden D. Feasibility of common carotid artery point of care ultrasound in cardiac output measurements compared to invasive methods. J Ultrasound. 2015;18:127-33.

46. Miller JB, Sen A, Strote SR, Hegg AJ, Farris S, Brackney A, Amponsah D, Mossallam U. Inferior vena cava assessment in the bedside diagnosis of acute heart failure. Am J Emerg Med. 2012;30:778-83.

47. Juhl-Olsen P, Vistisen ST, Christiansen LK, Rasmussen LA, Frederiksen CA, Sloth E. Ultrasound of the inferior vena cava does not predict hemodynamic response to early hemorrhage. J Emerg Med. 2013;45:592-7.

48. Zengin S, Al B, Genc S, Yildirim C, Ercan S, Dogan M, Altunbas G. Role of inferior vena cava and right ventricular diameter in assessment of volume status: a comparative study: ultrasound and hypovolemia. Am J Emerg Med. 2013;31:763-7.

49. Corl K, Napoli AM, Gardiner F. Bedside sonographic measurement of the inferior vena cava caval index is a poor predictor of fluid responsiveness in emergency department patients. Emergency Medicine Australasia. 2012;24:534-9.

50. Blehar DJ, Dickman E, Gaspari R. Identification of congestive heart failure via respiratory variation of inferior vena cava diameter. Am J Emerg Med. 2009;27:71-5.

51. Weekes AJ, Lewis MR, Kahler ZP, Stader DE, Quirke DP, Norton HJ, Almond $C$, Middleton D, Tayal VS. The effect of weight-based volume loading on the inferior vena cava in fasting subjects: a prospective randomized doubleblinded trial. Acad Emerg Med. 2012;19:901-7.

52. Anderson KL, Jenq KY, Fields JM, Panebianco NL, Dean AJ. Diagnosing heart failure among acutely dyspneic patients with cardiac, inferior vena cava, and lung ultrasonography. Am J Emerg Med. 2013;31:1208-14.

Ready to submit your research? Choose BMC and benefit from:

- fast, convenient online submission

- thorough peer review by experienced researchers in your field

- rapid publication on acceptance

- support for research data, including large and complex data types

- gold Open Access which fosters wider collaboration and increased citations

- maximum visibility for your research: over $100 \mathrm{M}$ website views per year

At BMC, research is always in progress.

Learn more biomedcentral.com/submissions 